\title{
Key Technology of South Sea Pearl Industry Management Information Service Platform Based on the Internet of Things
}

\author{
Longqin $\mathrm{Xu}^{1, *}$, Shuangyin $\mathrm{Liu}^{1,2}$, and Daoliang $\mathrm{Li}^{2}$ \\ ${ }^{1}$ College of Information; Guangdong Ocean University, Zhanjiang Guangdong 524025, China \\ ${ }^{2}$ College of Information and Electrical Engineering, China Agricultural University, \\ Beijing, P.R. China 100083 \\ $\{x l q l w, h d l s y x l q\} @ 126$. com
}

\begin{abstract}
This research constructs the south sea pearl industry management information service platform based on the Internet of Things, analyzing the features and technical advantages of Internet of Things, as well as the current existing problems of the pearl Industrial management. We have investigated the application management model of the Internet of Things in the product flow of pearl industry from production to processing management and explored the application of the key technologies, like radio frequency identification (RFID), wireless sensor network (WSN), physical markup language (PML) and the Electronic Product Code (EPC), to the Internet of Things in the pearl industrial management information services application platform. With the hope to bridge and eliminate the gap caused by differences in technology and standards among various sectors in the South Sea pearl production, processing, marketing and distribution, thus integration and optimization of pearl industrial management will be promoted and developed healthily.
\end{abstract}

Keywords: Internet of things, Pearl industry, WSN, RFID, EPC, PML, Cloud computing platform.

\section{Introductions}

China is one of the countries which is first to culture pearls, and has become the world's major pearl farming country in the late 20th century, accounting for $96 \%$ annually pearl production in the world, about 30 tons of them are sea water pearls, of which about $60 \%$ is mainly from Zhanjiang, Guangdong[1]. Pearl is not only a traditional Chinese herbal medicine and qualified facial products, but also a major channel to increase coastal pearl farming income. With concentration and support of all levels governments, pearl industry in Zhanjiang has been rapidly developed in recent years. However, in the huge production and consumption of the pearl industry, there are still problems[1-2] as follows: 1) The model of current Sea water pearl

${ }^{*}$ Corresponding author. 
farming descended traditionally, which consumes a lot of resources and extensively cultivated. New products and technologies cannot be fast promoted, which produces low value-added products; 2) Low level of information collection and control in sea water pearl process of production and in short of water management system for the whole process of pearl production, thus resulted in low level of industrialization; 3) With substandard and unreasonable feeding, spraying, fertilizing, resulted in higher cost as well as risks of investment for formers; 4) Over farming with high-density caused environmental pollution and deterioration of sea water as well. The experience is far enough to clearly get to know the pearl growth environment, which is impossibly assisted by current techniques and disease resistant warning mechanism of sea water pearl poorly works; 5) Lacking of information, irrational expansion of the scale, and unsmooth channel in sales and cyclical fluctuations in market conditions, which hurt the enthusiasm of farmers; 6) without a set of pearl industrial management system to cover the whole process of production, the current information systems in this field is only suits for a single enterprise system and a single custom developed, which resulted in diversified description of pear introduction and the waste of resources and the development of modern management is blocked.

In this paper, for the existing problems in the management of the whole process of sea water pearl production in Guangdong areas, we has built the pearl industrial management information services platform based on the Internet of Things which combines pearl cultivation and processing techniques, networking technology and intelligent information processing technologies, to achieve the automatic production process control product traceability and scientific management of sea water pearls. Then high yield, efficient, safe, and healthy farming and sustainable development water pearl could be possible.

The research on morphological characteristics of corn seed had got good identification results while much less study of corn purity identification and much more application about corn side features. This paper proposed that the color features of crown core area had significant function on corn purity after the study on three commonly used maize varieties. The DBSCAN was optimized by farthest first traversal algorithm for the purity identification. The experimental result indicated this method had high classification rate and the higher precision and offered a reference for building accurate purity identification system.

\section{Internet of Things and Working Principle}

\subsection{The Concept of Internet of Things}

Internet of things is a network which combines information sensing devices such as the smart sensors, radio frequency identification (RFID), laser scanners, global positioning system (GPS), in accordance with the agreed protocol, to connect Internet with anything, to exchange information and communication in order to achieve intelligent identification, positioning, tracking, monitoring and management[4-5]. 


\subsection{Internet of Things in the Current Development Home and Abroad}

Currently, in Japan, the United States, South Korea, EU and other countries corresponding policy has been introduced in support of the development of internet of things, and has made a lot of basic research and application development.

In the United States and Europe, internet of things have greatly developed in intelligent power, intelligent home, intelligent transportation, intelligent logistics, ecological monitoring, e-health and other fields[6]. IBM proposed the concept that "wisdom of the Earth, internet of things and cloud computing" which leads the new round of IT technology revolution in 2009 [7].

The starting and development in internet of things in our country has not lagged behind other countries, and a long-term planning "next-generation broadband mobile wireless communications network" has been made, which specially focuses on the research and development of "sensor and its network."

Premier Wen Jiabao proposed "Feel China" when visiting Wuxi on August 7, 2009. The concept of internet of things in China has attached great importance and become a new wave core areas after the computer, Internet, mobile communications information industry.

Some provinces have a large number of domestic uses of sensor networks to solve the power, agriculture, fisheries and transport in the "M2M" and other information and communication services[6-9]. In the future things will not only penetrate into the smart city, smart transportation, smart homes, public safety, environmental protection and other fields, but also greatly promote the economic development, which is seen as a new emerging industries.

\subsection{Workflow of Internet of Things}

The basic work flow of internet of things is composed by the entity markup language Information Server (Physical Markup Language Information Server, PML-IS), information collection system, the object name server (Object Name Service, ONS) and information management system [6]. The function of each is as follows:

1) Information collection system. The system includes wireless water sensors, weather sensors, RFID tags, wireless sensor network (WSN), readers (reader) $\backslash$ GPRS wireless communication, data exchanging, monitoring and management software, mainly to complete the collection of the water environmental factors, transmission and storage, in order to achieve automatic information collection for farming environment. The information is transferred by wireless sensors and GPRS connection to the central server which handles the processor installed in information processing software, such as the collected data conversion, analysis, comb, integrity checking, data recovery and other operations, the processed data to the appropriate database management software for individual use.

2) The object name server (Object Name Service, ONS)[6]. The ONS server main function is achieving correlation between the various sensor points and PML-IS 
server and established the maps with ecological information on pearl breeding, pearl Electronic Product Code EPC tag and the PML description of pearl product.

3) Physical Markup Language Information Server, PML-IS.[6]. The user can first create and maintain data, define the rules, and then the user can product a code in accordance with predetermined rules of pearl, and then use the XML information on the items described in detail in order to facilitate access to other servers.

4) Information management system. The system with the help of hardware and software to obtain environment, processing and production management information in the whole process of pearl production management, products information is provided through the mapping between the object name server information and the PML-IS server retrieving the detailed description about the product in the PML-IS Information Server for pearl farmers and consumers, such as information search, product traceability and other functions in the form of the Web, also users can master all process of pearl production status by phone or wireless PDA.

\subsection{The Application Model of Internet of Things in the Pearl Industry Management Network Information Service Platform}

The application of the internet of things in pearl industrial management information service platform, whose advantage has been taken to reach seamless in monitoring and management containing sea water pearl production, processing and product traceability. The diagram is shown in Figure 1.

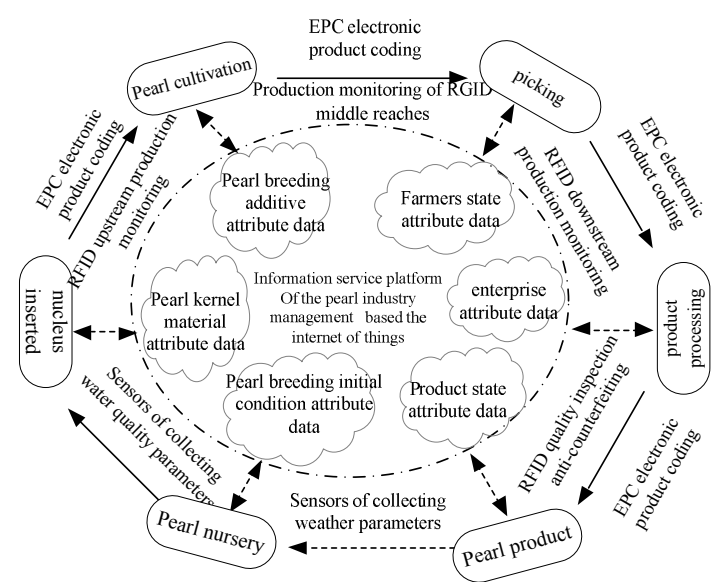

Fig. 1. Internet of things based pearl industrial information service platform structure diagram

As shows in Figure 1, Internet of things has achieved environment information collection, pearl product identification and monitoring by smart sensors and RFID and completed the mapping among pearl environmental information, the Electronic Product Code EPC tags and the PML-IS server by The ONS server which has achieved correlation between the various sensor points and PML-IS server in the processing of products such as the nursery, nucleus inserted, rest, picking. All 
information can be optimized through the pearl industrial information service platform transferred by a wireless or wired network. That can make the existing internal management system to be compatible with the maximum and became integral part of internet of things.

RFID, WSN and electronic product code (EPC) are integral essential factors in the pearl industry. It will effectively monitor and convert data each other in all aspects of the process in sea water pearls farming, product processing and product distribution, to establish a landmark product and quality of traceability; the standardization and unified of data collection, transmission and seamless in sectors of production in the pearl industry will also be achieved.

\section{Pearl Industrial Management Information Service Platform}

\subsection{System Goals}

For the realization of intelligent processing and digitization process in south sea pearl production, the pearl industrial management information service platform has been established with key technology of the Internet of Things, artificial intelligence and expert systems theory and computer-assisted decision-making strategies development. On this account, it will improve the standard of management and production process of water pearl enterprises and farming on the level of pearl, thus the intensive pearl industry development and scientific management is secured.

\subsection{System Architecture Design}

The system is divided into data acquisition layer, transport layer, data servers, business logic (functional layer) and the presentation layer with the use of the N-tier B/S structure mode; Development platform uses NET Framework which effectively reduces the system client requirements, and the distribution of the client applications and version control problems will be avoided. System architecture is shown in Figure 2.

In architecture, the presentation layer has completed the function of interface interaction with the end-user, and the applications layer_has .aspx page and related code; Business logic layer is used to encapsulate business rules and business logic, which is packaged as. NET components in the application layer. Data server layer has adopted the layer style persistence (CMP) design pattern with container, in which pattern the business object data does not consider where the original data is from and how to store it, as long as the data access components interact with data server (or servers ), all data is manipulated through stored procedures. 


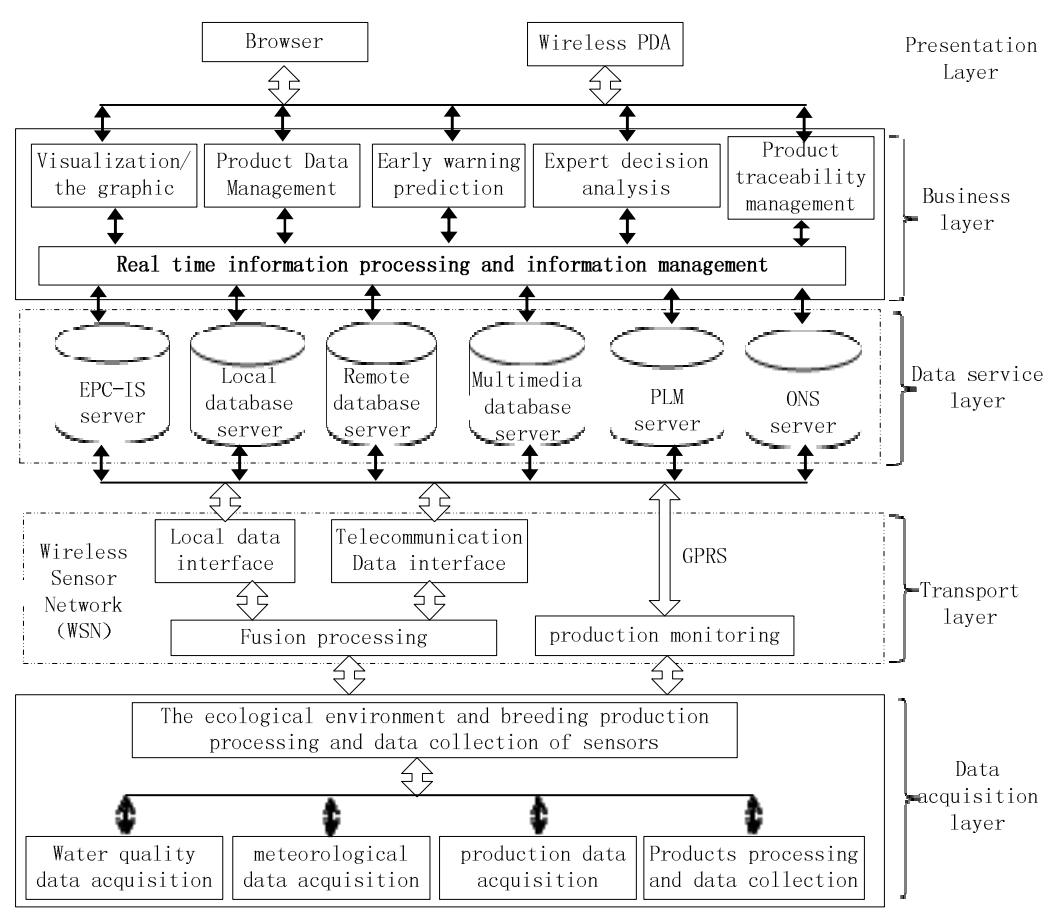

Fig. 2. Architecture diagram of Internet of things based pearl industrial information service platform

\subsection{System Features Module Design}

According to actual needs of the majority of pearl farmers and management staff of enterprises and institutions, in addition to problems of existing software systems are badly in need of upgrading, as well as independence of pearl farming industry model and complexity of culturing in the process of breeding, feeding, disease prevention and control management, such as insertion of nuclear, fishery drugs, disinfection, rest, oxygen, microscopic examination, testing, painting, drilling, water quality control and so on, these large number of knowledge is classified through theoretical guidance such as information intelligent perception, artificial intelligence, expert systems and knowledge engineering, to sort out their internal relations, and optimize the combination of knowledge based on expression of a variety of methods. With research of the knowledge of high effective south sea pearl production model to built pearl databases, production and processing information database, disease diagnosis prevention and treatment knowledge database, then shared south sea pearl management information service platform is set up and rebuilt for the pearl industry to provide assisted strategic supplementary decision for south sea pearl enterprises and units.

The functions of this platform includes: environmental data collection and management, prediction and warning, water quality control management, production 
management, quality and traceability management, expert systems, supply and demand information, farming techniques information, processing technology information, technical services, expert consultation, decision analysis, system maintenance. So users can easily use this system in multi-angle multi-channel. The system function structure is shown in Fig.3:

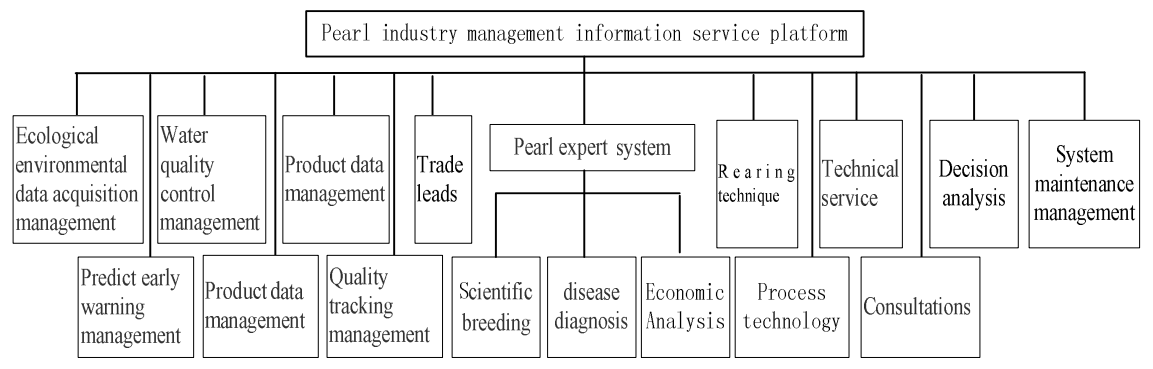

Fig. 3. Function structure of management information service platform based on Internet of things

Through the pearl industrial management information services platform, pearl farming information services in prenatal and postnatal and science information, aquaculture management and remote intelligent decision-making services in products are provided; effectively achieve a smooth channel for the transformation of pearl culture technology, significantly enhance the quality of sea water pearls, greatly improve production and promote sea water pearl industry's enthusiasm for aquaculture and create the northern Gulf region "pearl" industry. While the research institutes of the new technology, new achievements and new products in the marine pearl culture in the promotion of the use can increase the stocking density, shorten the breeding cycle, reduce farming risk, reduce production costs and improve the level of aquaculture technology and quality control, reduce labor intensity, expand production scale, advance the automation of production management, putting forward pearl culture toward equipment engineering, digital culture, information-oriented, which has great scientific significance and practical value in the healthy development of pearl industry.

\section{Analysis of Key Technology and Its Applications in Internet of Things}

\subsection{Wireless Sensor Network (WSN)}

WSN is the key information technology in the pearl culture industry, the management environment monitoring and collection, which use wireless sensor node (Node) to collect and perceive farming environment information, and timely send or receive information with aggregation node (Sink).[9] Connected the DNS cloud server, onsite monitoring center with aggregation node (Sink) of wireless sensor network through the RS-232 serial cable or GPRS , forming on-site real-time information collection system(Figure 4) 


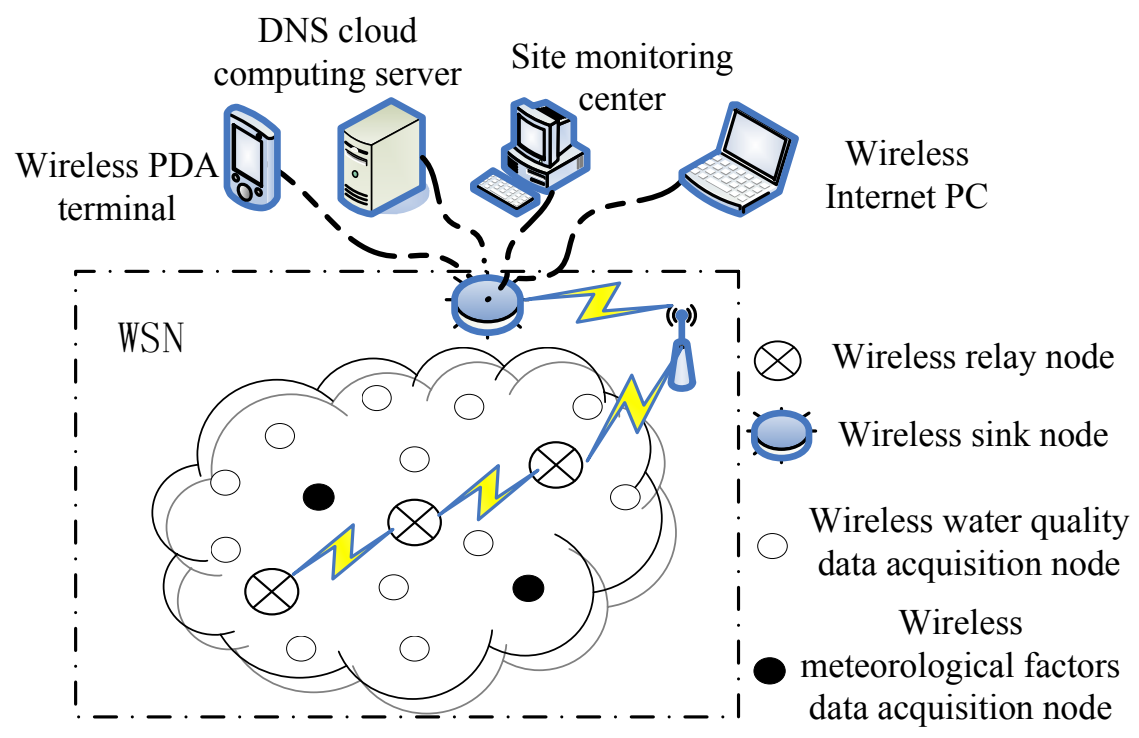

Seawater cultured pearl water quality parameters of meteorological data collection area

Fig. 4. Application of WSN technology in pearl industry management

While monitoring seawater pearl environmental information on-site with the wireless sensor networks, we deploy a certain number randomly sensor information collection nodes in the pearl farming region, each node can form wireless sensor network by self-organizing. The data monitored by sensor nodes can be transmitted and processed through multi-hop route between other sensor node and the sink node (base station) [10], and then transmitted via the GPRS or Internet monitoring center to the scene, server or terminal device.

The pearl industrial management information service platform based on internet of things is in use of the wireless sensor nodes which have integrated solar panels, lowpower and the $433 \mathrm{MHz}$ communication frequency based on the thought that pearl farms has larger areas for information collection, so nodes is distributed, and cable power supply is not convenient and monitoring and collection for eco-environmental factors and other characteristics is dynamic. Communication distance between nodes is $500 \mathrm{~m}$, and communication speed can reach $76.8 \mathrm{kbps}$, thus achieve the real-time dynamic acquisition and transmission for water quality and climate pearl farming environment factors.

\subsection{RFID}

RFID is encoding vector in the process of pearl production, processing and product distribution, which transform environment information collected by the WSN, production, processing chain to the corresponding coding and record in the RFID chip, the application model is shown in Figure 5. RFID tags of pearl products are 
scanned by the sensor, then the code analysis is transmitted to the local coding system for data processing; ONS is responsible for queries and mapping management with processing Electronic Product Code EPC and the corresponding PML-IS server address; Information through the network will be transferred to DNS cloud computing services platform for the information management with other aspects of pearl culture [11]. RFID has the advantages of automatic sensing, transmission information content, Mass and dynamic storage, and can record with multi-dimensional pearl industry-related information; also coding hidden to prevent malicious copy, safe and reliable without human intervention and so on.

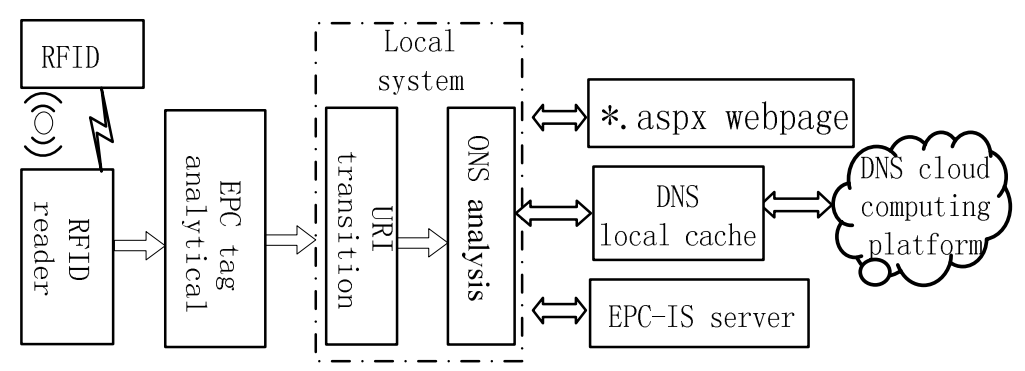

Fig. 5. RFID application model

\subsection{Electronic Product Code （EPC）}

EPC code (electronic product code) is the Auto-ID Center which is assigned to each physical target with only sign of the query code, it includes a string information on behalf of pearl and production categories and its ID, the date of the various stages of cultivation, production dates of purchase, production date, manufacturer, expiration date, pearl processing date [12]. Meanwhile, with the whole process of pearl farming in the various aspects of changing, the production management data can be updated in real time. Typically, EPC code can be made of silicon into electronic tag and attached to kernel of pearl to be identified, transferred and checked by information-processing software. When the pearl products through the data collection authorized points, it is not only correctly read the code of the unique pearl products but also read out of production with other inter-relate through the ONS system and PML system, so as to achieve the seamless of all aspects and improve management efficiency pearl industry.

Pearl industry standard EPC code and coding rules need to be encoded by the national standards and industry research institutions and departments jointly developed, comprehensive, unambiguous, practical, scalable and open, etc., are common pearl culture industry compliance with coding standards and rules, which can effectively eliminate all aspects of pearl production and processing of fault information management, enhance the management efficiency of pearl farming. 


\subsection{PML Entity's Markup Language}

PML is a standardized language, which helps user to define rules and maintain the data, can be coded with information about the name of pearl products, categories, attributes of the breeding, production and processing status, production and other aspects of information according to the rules in advance and use XML to descript the product information [13-15]. It solves problem of the limited capacity of electronic tag storage without saving a lot of physical information. Concerning the Internet of Things, PML server is mainly used to provide a common mode of the original information items defined in the rules, to facilitate the access to other servers.

\subsection{Technology Integration}

According to the demand of south sea pearl industry management and technique expansion, integrated technology services concept is adopted, sensor networks, distributed technology, artificial intelligence, forecasting and decision-making, gray theory, artificial neural networks, hybrid intelligent diagnostic reasoning, fuzzy reasoning, database technology, MIS Technology, Rich Internet, WebGIS technology and disaster monitoring and early warning technology etc. is integrated. This platform with integrated hardware and software, large-grained, loosely coupled, dynamic binding characteristics, overcomes differences in shielding characteristics of a heterogeneous network.

Pearl industry management information service platform that contains pearl and pearl products processing and marketing enterprise business applications, including local, covering pearl breeding, processing, distribution and the whole process, before, during and post-natal and other various links on the River platform, according to a unified transport protocol, EPC encoding, ONS system via a wired or wireless networks, relying on the local computing and cloud computing to support distributed on the basis of the built; pearl cultivation and processing in accordance with the upper, middle and lower reaches various aspects of water quality and meteorological sensors transfer the state property, state property of production, processing, deployment of personnel, operating environment, complete the quantity, quality control and direction of information flow and feedback intelligent deployment, from "farm to the sales counter." The seamless link for the pearl quality control, production information management, creating brand offers reliable protection.

\section{Conclusions}

We explore the technology of on internet of things in the pearl industrial management information services application platform focusing on the current pearl industrial management problems. It combines the Internet with pearl industry, and restricts the Pearl environmental information, various aspects of production factors, product 
processing and marketing of pearl. It has become a modern information technology to drive the fisheries modernization.

Considering characteristics of cultured pearl industry and culture of enterprise information progress, the application of things is not so easily to realize, it is the integration of multiple technologies and integration of multiple applications in a systematic works, some key technology such as transfer protocol, integrated and embedded technology and information security and so on still need further improvement. In the future, the gradual integration of networking technology into pearl culture industry management will push forward the healthy and sustainable aquaculture industry development.

Acknowledgements. This research is financially supported by the China Spark Program Project (2007EA780068), Guangdong Science And Technology Program Project (2010B020315025) and Zhanjiang Science And Technology Program Project (2010C3113011).

\section{Reference}

1. Li, Z.: Economical analysis of dilemma of chinese pearl industry and outlet. Research of Agricultural Modernization 28(4), 443-445 (2010)

2. Yi, L.: Development strategies of "south pearl" industry in Zhanjiang. Chinese Fisheries Economics 27(5), 36-42 (2009)

3. Wang, Z., Zhang, C.: EPC and Internet of thing. China standards press, Beijing (2004)

4. Wen, J.: In 2010 the government work report (EB/OL). (March 15, 2010), http: / / www.gov.cn/20101h/content-1555767.htm (May 15, 2010)

5. Sun, Q.-B., Liu, J., Li, S.: Internet of things: summarize on concepts, architecture and key technology problem. Journal of Beijing University of Posts and Telecommunications 33(3), 1-9 (2010)

6. Commission of the European communities, COM (2009) 278 final. Internet of things an action plan for Europe, Brussels(EB/OL). (June 18, 2009),

http: / / ec.europa.eu/information_society/ policy/rfid/documents/commiot2009.pdf

7. South Korean Ministry of Information and Communication. South Korea plans to 2012 networking infrastructure building internet of things (December 4, 2009),

http: / / www.c114.net/news/17/a450913.html

8. European Research Projects on the Internet of Things (CERP-IoT) Strategic Research Agenda(SRA).Internet of things-strategic research roadmap (September 15, 2009), http://ec.europa.eu/information_society/policy/ rfid/documents/in_cerp.pdf

9. Zhu, W., Qi, W., Xiaoqiang, H.: The Design of the Remote Water Quality Monitoring System based on WSN. In: Proceedings of 5th International Conference on Wireless Communications, Networking and Mobile Computing, WiCOM, pp. 3639-3644 (2009)

10. Cao, Y., Wang, X.: Design of Farmland Weather Monitoring System Based on WSN. Research of Agricultural Modernization (12), 163-165 (2008) 
11. Liu, Q., Cui, L.: Key Technologies and Applications of Internet of Things. Computer Science 37(60), 1-5 (2010)

12. Li, L., Zhu, Q.-X.: Research on middleware of EPC system. Computer Engineering and Design 27(18), 3360-3363 (2006)

13. He, K.: The Key Technologies of IOT with Development \& Applications. The Key Technologies of IOT with Development \& Applications (3), 32-35 (2010)

14. Tim, W., Peter, C., Pavan, S., et al.: Transforming agriculture through pervasive wireless sensor networks. IEEE Pervasive Computing 6(2), 50-57 (2007) 